\title{
A gestão social sob a ótica do referencial de Michel Foucault
}

\author{
The social management under the optics of Michel Foucault's referential
}

Rogério Faé

Doutor em Administração pela Universidade Federal do Rio Grande do Sul (UFRGS), professor adjunto da Escola de Administração da Universidade Federal do Rio Grande do Sul (UFRGS), Porto Alegre, RS Brasil, e-mail: rogerio.fae@ufrgs.br

Recebido: $15 / 12 / 2010$ Received: $12 / 15 / 2010$

Aprovado: $13 / 04 / 2011$ Approved: 04/13/2011

\section{Resumo}

Gestão social tem se caracterizado como um conceito-chave que abrange uma série de práticas que oscilam desde ações gerencialistas direcionadas para a simples manutenção ou atualização do sistema capitalista até formas de produção qualificadas como anticapitalistas (Fischer, 2002). Entende-se gestão social como enunciado contido em um campo discursivo - que é definido como espaço no qual é possível a análise de um enunciado considerado em sua singularidade, a partir da compreensão das condições de sua existência, da definição de seus limites e de suas correlações com outros enunciados (Foucault, 2000). Sendo assim, este ensaio foi pensado com o propósito de analisar, sob a ótica do referencial de Michel Foucault, algumas das formas de articulação da prática discursiva que valoriza a gestão social como instrumento de manutenção e reforço da lógica capitalista de mercado, qualificada como formação discursiva predominante no contexto em que estamos inseridos. Assim direcionado, este texto inicia com a introdução de alguns dos aspectos do referencial foucaultiano que serão relevantes para a análise ora proposta. Quanto às estratégias verificadas no campo em estudo, serão examinadas: a) a articulação proporcionada pela lógica sistêmica no campo da gestão social, principalmente em aspectos que possibilitam o direcionamento dos esforços para o desenvolvimento; b) estratégias utilizadas pelos organismos financiadores internacionais e, mais especificamente, pelo Banco Mundial para influenciar os processos de cooperação técnica; e c) a forma de incorporação a este campo do conceito de capital social, conforme proposto por Francis Fukuyama (1996; 2006) e por Pierre Bourdieu (1980).

Palavras-chave: Gestão social. Práticas discursivas. Banco Mundial.

\section{Abstract}

Social Management has been characterized as key concept that includes a series of practices ranging from generalist actions directed to the simple maintenance or use of the Capitalism to forms of production described as anti-capitalist (Fischer, 2002). Social management is understood as an enouncement comprised in a discursive field - defined as an space where it is possible to analyze an enouncement considered in its singularity, from the understanding of the conditions of its existence, of the definition of its limits and of its correlations with other enouncements (Foucault, 2000). So, this essay was conceived in order to analyze, under the optics of 
Michel Foulcault's referential, some of the articulation forms of the discursive practice that value the social management as instrument of maintenance and reinforcement of the market capitalist logic, described as a prevailing discursive formation in the context. In this way, some aspects of the Foucault's referential, which will be relevant for the analysis proposed now, are mentioned in the beginning of this text. In relation to the study field, the following strategies will be analyzed: a) the articulation provided by the systemic logic in the social management field, mainly in aspects that enable to direct these efforts to development; b) strategies used by the international financial organisms and, more specifically, by the World Bank, in order to influence the technical cooperation processes; and c) the form of incorporation of the social capital concept to this field, as proposed by Francis Fukuyama (1996; 2006) and Pierre Bourdieu (1980). .

Keywords: Social management. Discursive practices. World Bank.

\section{Introduç̃̃o}

Gestão social tem se caracterizado como um conceito-chave que abrange uma série de práticas que oscilam desde ações gerencialistas direcionadas para a simples manutenção ou atualização do sistema capitalista - objetivam promover a confluência dos sistemas econômico e social através do aprimoramento de instrumentos de gestão direcionados para a eficiência e eficácia das práticas sociais -, até formas de produção anticapitalistas (Fischer, 2002).

Este ensaio foi pensado com o propósito de analisar, sob a ótica do referencial de Michel Foucault, algumas das formas de articulação da prática discursiva que valoriza a gestão social como instrumento de manutenção e reforço da lógica capitalista de mercado, qualificada como formação discursiva predominante no contexto em que estamos inseridos. Assim direcionado, este texto inicia com a introdução de alguns dos aspectos do referencial foucaultiano que serão relevantes para a análise ora proposta.

Quanto às estratégias verificadas no campo em estudo, serão examinadas mais detalhadamente: a) a articulação proporcionada pela lógica sistêmica no campo da gestão social voltada para o desenvolvimento; b) estratégias utilizadas pelos organismos financiadores internacionais e, mais especificamente, do Banco Mundial para influenciar os processos de cooperação técnica voltados à educação; e c) a forma de incorporação a este campo do conceito de capital social, conforme proposto por Francis Fukuyama $(1996$; 2006) e por Pierre Bourdieu (1980).

\section{A mútua produção sujeito-contexto}

Para Michel Foucault, surge na época clássica um esforço de construção de um método universal e sistemático de análise, que foi observado, principalmente, na proposta de Descartes. Tal método objetivava a produção de verdades inquestionáveis, por meio de uma ordenação capaz de entender o mundo através da comparação e ordenação (Foucault, 2000; Rabinow \& Dreyfus, 1995).

Para Descartes (2006), existe uma verdade de cada coisa e aquele que a encontrar conhece a seu respeito tanto quanto se pode conhecer. Nesse sentido, busca através de seu método aprender a seguir a verdadeira ordem e a enumerar exatamente todas as circunstâncias daquilo que procura. A proposta metodológica de Descartes objetivava, de forma gradativa, o aumento do esclarecimento, ou seja, o mais alto nível de esclarecimento possível a cada indivíduo.

0 papel do homem era esclarecer a ordem do mundo através de ideias claras e distintas que eram alcançadas por meio da representação, esta última servindo de suporte à elaboração de descrições artificiais da ordem natural preexistente. Entretanto, o que daí decorre é a construção de uma ordem convencional dos signos, na qual a linguagem garante a representação adequada. Construção que gera uma fusão entre o ser e a representação do ser, enquanto linguagem (Foucault, 2000; Rabinow \& Dreyfus, 1995).

Por consequência, “... na grande disposição da epistémê clássica, a natureza, a natureza humana e suas relações são momentos funcionais, definidos e previstos. E o homem como realidade espessa e primeira, 
como objeto difícil e sujeito soberano de todo conhecimento possível, não tem aí nenhum lugar" (Foucault, 2000, p. 427).

É no final do século XVIII e início do século XIX, com o fim da era clássica, que surge a possibilidade da emergência do homem como sujeito de conhecimento. Posição que lhe impulsiona à caminhada em direção à compreensão de si mesmo, tornando-se, assim, sujeito e objeto de seu conhecimento.

Naquele momento, a linguagem se transforma para o sujeito cognoscente em uma construção com história própria, na qual o próprio sujeito é o principal ator. Entretanto, a “... partir do momento em que a linguagem não é mais a responsável pela representação, possibilitando o conhecimento, a função de representar se torna um problema" (Rabinow \& Dreyfus, 1995, p. 31).

A preocupação que emerge do contexto já não é em relação à representação, mas sobre as formas pelas quais as coisas são dadas à representação, ou seja, em que condições, sob que contextos, que fatores tornaram necessária determinada emergência e não outra. 0 que decorre daí é uma inversão, onde existia uma metafísica da representação, passa a constituir-se uma analítica ${ }^{1}$ da finitude, de onde emerge um sujeito que ocupa a posição de organizador do contexto em que se insere (Foucault, 2000).

Para o autor, os próprios limites apresentados pelo conhecimento fundam a positividade do saber², ou seja, é com base na finitude que o homem poderá fundar, de forma positiva, sua possibilidade de ser.

Dessa posição emerge o entendimento de que o contexto, ao conter as possibilidades abertas ao sujeito, lhe é, ao mesmo tempo, o mais longínquo, como formação discursiva que escapa ao sujeito e que lhe determina as condições, e o mais próximo, ao assumir como suas e, assim, legitimar e definir as condições de manutenção das práticas discursivas em que se insere (Foucault, 2000).

Visto sob esse duplo aspecto, o homem emerge:
... (1) como um fato, entre outros fatos, para ser estudado empiricamente e, além disso, como a condição transcendental de possibilidade de todo conhecimento; (2) como cercado por aquilo que não se pode esclarecer (o impensado) e, além disso, como um cogito potencialmente lúcido, fonte de toda inteligibilidade; e (3) como o produto de uma longa história cujo início nunca poderá alcançar e, além disso, paradoxalmente, como a fonte desta mesma história (Rabinow \& Dreyfus, 1995, p. 34).

Assim, se nos duplos empírico/transcendental, cogito/impensado e recuo/retorno da origem há uma construção história que antecede o sujeito datado, também estão pressupostas estratégias que, ao mesmo tempo, conservem os limites estabelecidos e os ultrapassem, sendo essa relação fonte constante de novas realidades:

... a análise da finitude explica, do mesmo modo como o ser do homem se acha determinado por positividades que lhe são exteriores e que o ligam à espessura das coisas, e como, em troca, é o ser finito que dá a toda determinação a possibilidade de aparecer na verdade positiva (Foucault, 2000, p. 464).

\section{A questão da hegemonia}

0 conceito de hegemonia ganha forma com Gramsci (2002), que o caracteriza como uma forte unidade que prevalece em uma formação social concreta. Ao retomarem o conceito, Laclau e Mouffe (2001) argumentam que a hegemonia se origina em resposta a uma crise na qual se busca, através de recomposições e articulações, uma teoria totalitária.

A hegemonia para Laclau e Mouffe (2001) ganha status de consenso provisório, representativo de determinada classe controladora do contexto em pauta. Nessa condição, busca perpetuar-se através da manutenção de uma posição favorável em termos valorativos e de interesses em comum.

\footnotetext{
1 “... uma analítica é a tentativa de mostrar como são possíveis a representação e a análise das representações, e até que ponto podem ser legitimadas" (Rabinow \& Dreyfus, 1995, p. 31).

2 "Um saber é aquilo de que podemos falar em uma prática discursiva que se encontra assim especificada: o domínio constituído pelos diferentes objetos que irão adquirir ou não um status científico...; um saber é, também, o espaço que o sujeito pode tomar posição para falar dos objetos que se ocupa em seu discurso...; um saber é também o campo de coordenação e de subordinação dos enunciados em que os conceitos aparecem, se definem, se ampliam e se transformam...; finalmente, um saber se define por possibilidades de utilização e de apropriação oferecidas pelo discurso..." (Foucault, 2000a, p. 206-207).
} 
Por outro lado, a hegemonia, ao caracterizar-se como um processo dinâmico e, principalmente, ao sofrer o confronto de atores que não partilham das posições, seja em nível interno ou externo ao campo de equivalência, necessita se readequar e, nesse sentido, pode buscar a incorporação de novos aspectos sem, no entanto, abrir mão daqueles interesses considerados essenciais à sua existência. É exatamente nesse ponto que o movimento opositivo, entendido como resistência, pode abrir a possibilidade de enfraquecimento ou dissolução da especificidade da posição hegemônica.

Entretanto, Laclau e Mouffe (2001), ao proporem o conceito de hegemonia, constroem uma teoria que foca seus esforços de enfrentamento sobre um aspecto específico, por exemplo: contra a lógica capitalista, posição que tende a direcionar as lutas resistenciais contra uma característica objetiva. Essa postura é necessária à identificação de pontos de ataque, construção de estratégias de luta, principalmente, por possibilitar a defesa explícita de outra lógica que se oponha àquela predominante. Por outro lado, tal foco direcionado poderá dificultar o confronto ou o questionamento relacionado à lógica subjetiva, principalmente quando esta se direciona para a manutenção de privilégios e interesses flutuantes.

0 risco que daí emerge é de alteração exclusiva dos atores que estão no poder, ou pior, apenas na forma de exercer o poder no contexto, sem que haja real alteração na dinâmica da relação dominadores-dominados.

Tal posição pode ser mais bem analisada pela forma como o conceito de "positividade" é descrito por Mouffe e Laclau (2001, p. 128), na relação colonizado-colonizador:

... a determinação positiva do colonizador em oposição ao colonizado não cria um sistema de posições diferenciais positivas entre os dois, simplesmente porque ele dissolve toda positividade: o colonizador é discursivamente construído, assim como o anti-colonizador. Em outras palavras, a identidade vem a ser puramente negativa. Isto porque a identidade negativa não pode ser representada de um modo direto... ela somente pode ser representada indiretamente, através da equivalência entre seus momentos diferenciais.

Sob tais premissas, a positividade só é possível em momentos nos quais as características diferenciais são explicitadas no campo em questão. $\mathrm{Ou}$, em outras palavras, quando existirem posições antagônicas e as partes estiverem em condições de lutar abertamente pelo controle da situação.

Em contraponto, para Foucault (2000a), a positividade é uma posição de rompimento e de construção de alguma coisa. Nesse sentido, a construção de uma relação entre colonizado e colonizador é positiva em si mesma, ou seja, enquanto construção de determinada prática discursiva que sempre é provisória, como visto anteriormente. Cabe salientar que a construção proposta pelo autor pode incorporar, além das lutas abertas, outras formas encobertas de luta como: sabotagens, hostilizações, passividade que gera ganhos secundários, outras formas de incorporação das regras vigentes e, até mesmo, alterações provocadas por acidentes imprevistos e imprevisíveis até que ocorram.

É relevante destacar aqui o conceito de práticas discursivas como produções do poder, que atravessam e são atravessadas por um saber que perpassa os diversos níveis e estruturas institucionais, criando possibilidades de readequação ao/do contexto através da atualização do discurso segundo as condições abertas no campo (Foucault, 1996).

As práticas discursivas podem ser entendidas como a articulação de saberes específicos a determinado campo; caracterizam-se por sua parcialidade e constante mutabilidade conforme as forças presentes no contexto; e estão em constante construção.

A produção de práticas discursivas é influenciada por movimentos que se atravessam de forma a se reforçarem, conviverem ou oporem de maneira flutuante a cada momento e contexto. Dessa forma, tal conceito se caracteriza por movimentos constantes que buscam manutenção, convivência ou que impõem oposição e/ou resistência.

Com vista à continuidade do texto, é relevante, neste ponto, definir a forma como o conceito de resistência é pensado neste artigo.

\section{Resistência}

Ao pensar a questão da resistência, a proposta lacaniana destaca-se, mesmo que isto exija um esforço de adequação do conceito construído sob a lógica da clínica psicanalítica para a esfera organizacional.

Lacan (1985, p. 204), ao definir que o inconsciente - como instância desorganizada que busca a realização da energia vital ou pulsão - se estrutura como linguagem, remete às práticas 
discursivas a própria possibilidade de constituição dos sujeitos sociais:

Logo que a fala verdadeira emerge, mediadora, ela faz deles dois sujeitos muito distintos daquilo que eram antes da fala. Isto quer dizer que eles só começam a ser constituídos como sujeitos da fala a partir do momento em que a fala existe...

Entretanto, o que está na fala só pode ser reconstruído pelo sujeito, o objeto original está definitivamente perdido. Tal utilização da linguagem só é possível ao sujeito pelo não direcionamento $a$ priori da energia pulsional, o que torna o desejo apenas desejo de desejar algo (Lacan, 1985).

Segundo o autor, é possível aos sujeitos interpretações singulares sobre o ideal proposto em determinada formação discursiva a partir das condições abertas pela fala, ou melhor, é vital aos diversos sujeitos interpretações subjetivas que lhe constituam ao mesmo tempo de forma genérica, conforme as condições presentes na fala, e de forma singular, conforme a possibilidade individual de apropriar-se dos espaços abertos pela linguagem.

Assim, “... a resistência é o estado atual de uma interpretação do sujeito. É a maneira pela qual, naquele momento, o sujeito interpreta o ponto em que está. Esta resistência é um ponto ideal abstrato" (Lacan, 185, p. 287).

A resistência não é um obstáculo à constituição do sujeito, ela é sua condição; sem a qual o sujeito estaria preso a uma lógica estrutural que lhe definiria e fixaria as alternativas de ser no mundo. Esse, provavelmente, seja o ideal social ao qual Huxley nos alertou em Admirável Mundo Novo, ou que Skinner idealizou em Wolden II.

Lacan (1985, p. 287), em discurso proferido a analistas sobre a prática clínica, defende a seguinte tese:

A resistência é, propriamente falando, uma abstração que vocês colocam aí dentro para se orientarem.... Até aí está perfeitamente correto. Mas se daí forem chegar à ideia de que a resistência deve ser liquidada, como se escreve a toda hora, cairão no absurdo puro e simples.... Existe apenas uma resistência, é a resistência do analista. $\mathrm{O}$ analista resiste quando não entende $o$ que tem que lidar. Não entende com o que tem que lidar, quando crê que interpretar é mostrar ao sujeito que, o que ele deseja, é tal objeto sexual. 0 que ele imagina aqui como sendo objetivo é apenas pura e simples abstração.
Interessa salientar dois pontos: 1) em relação ao termo "resistência", propõe-se sua inversão: de uma lógica opositiva a determinadas práticas passa a uma condição de defesa de outras lógicas, interesses ou pontos de vista - se há resistência, não é, simplesmente, pelo desejo de se colocar contra, mas por posicionamento contrário fundamentado em outra lógica, com base em interesses e visões que podem ser parcial ou totalmente incompatíveis com os valores contra os quais está em confronto; 2) a posição do analista, conforme definida acima, pode ser pensada conforme proposto por Foucault (1993a; 2000a) como participante de um campo especifico e, por consequência, atravessada por determinados conhecimentos estabelecidos por meio de embates entre as partes que buscam o controle hegemônico e permanente do campo de lutas.

Nesse último aspecto, o movimento observado no analista que tenta impor sua visão, assim como no paciente que opta por alternativas diferentes daquelas propostas pelo analista, é entendido como defesa de conhecimentos e/ou percepções potencialmente utilizáveis. Tal processo pode, ainda, ser utilizado como metáfora a posturas semelhantes observadas nos diversos atores que participam dos mais variados campos, entre eles o organizacional e, neste trabalho, mais especificamente, o campo da gestão social.

Assim, indo ao encontro da proposta foucaultiana no que se refere à condição de todo ator, ao constituir-se como sujeito inserido em determinado discurso, sofrerá a influência do contexto que lhe abre as condições de reconhecimento e produção num determinado campo. Entretanto, a forma como cada sujeito interpretará esse discurso, identificando-se ou não com ele, dependerá das formas alternativas com as quais teve contato e, principalmente, de sua maneira de pensar o contexto; pensamento este que, ao ser externalizado, influenciará na manutenção ou na alteração do contexto como um todo (Foucault, 1990).

Cabe salientar que a opção de Foucault (2006, p. 69-70) foi pela contínua tentativa de abertura de possibilidades de alteração do contexto:

Eu sou um pirotécnico. Fabrico alguma coisa que serve, finalmente, para um cerco, uma guerra, uma destruição. Não sou a favor da destruição, mas sou a favor de que se possa passar, de que se possa avançar, de que se possa fazer caírem os muros. 
Um pirotécnico é, inicialmente, um geólogo. Ele olha as camadas do terreno, as dobras, as falhas. 0 que é fácil cavar? 0 que vai resistir? Observa de que maneira as fortalezas estão implantadas. Perscrutam os relevos que podem ser utilizados para esconder-se ou lançar-se de assalto. Uma vez tudo isto bem delimitado, resta o experimental, o tatear. Enviam-se informes de reconhecimento, alocam-se vigias, mandam-se fazer relatórios. Define-se, em seguida, a tática que será empregada. Seria o ardil? 0 cerco? Seria a tocaia ou bem o ataque direto? 0 método, finalmente, nada mais é que esta estratégia.

Para o autor, o trabalhar ou fabricar alguma coisa traduz-se, permanentemente, na tentativa de pensar algo ainda não pensado e de fazer emergir alguma coisa que não existia até então.

Nessa perspectiva e à semelhança da proposta lacaniana, a resistência se caracteriza como a defesa dos próprios interesses em um campo de lutas, no qual há cruzamentos de várias ordens: mútuo apoio, reforço, identificação de visões e objetivos, convivência, hostilização, conflito ou confronto direto. É exatamente nesse campo relacional, em constante alteração, que se abrem as possibilidades para a emergência e construção de novas alternativas.

\section{0 conhecimento como discurso verdadeiro}

Ao pensar a questão do conhecimento, destaca-se uma citação de Gadamer (1997, p. 11), que, em sintonia com a ideia central deste texto, pode servir como mais um ponto de reforço: “... compreender não é compreender melhor, nem saber mais, no sentido objetivo, em virtude de conceitos mais claros.... Bastaria dizer que, quando se logra compreender, compreende-se de um modo diferente".

Compreender, nesse texto, é entendido como a apropriação de determinado conhecimento, ou seja, sua adequação, por parte de cada sujeito, às condições singulares experimentadas e conforme as possibilidades abertas em determinado contexto localizado temporal e geograficamente. Isso pressupõe a possibilidade aberta aos sujeitos, mediante condições existentes no campo de lutas, de construção de algo até então impensado (Foucault, 1990).
Para este último autor, o conhecimento é entendido como uma produção do campo relacional, sendo:

... uma certa relação estratégica em que o homem se encontra situado. É essa relação estratégica que vai definir o efeito de conhecimento e por isso seria totalmente contraditório imaginar um conhecimento que não fosse em sua natureza obrigatoriamente parcial, obliquo, perspectivo.... Pode-se falar do caráter perspectivo do conhecimento porque há batalha e porque o conhecimento é efeito desta batalha (Foucault, 1999, p. 25).

O conhecimento somente emerge envolto num complexo sistema de saber e de poder ${ }^{3}$ que abre as condições para a formação de determinados sujeitos de conhecimento, assim como de determinadas relações de verdade (Foucault, 1999).

Pensar a apropriação do conhecimento em qualquer área pressupõe a avaliação do campo em que os atores interessados em determinada temática estão inseridos. Nesse sentido, Foucault (1999), ao defender a tese de que toda posição num campo discursivo, seja ela individual, grupal ou social, resulta de uma determinada forma particular de relação de forças entre os atores que compõem o campo, pressupõe a impossibilidade do conhecimento descontextualizado, ou seja, fora do campo de análise ou mesmo numa reconfiguração das relações que compõem o contexto, a especificidade de um objeto poderá ter seu valor significativamente alterado.

Dessa forma, o conhecimento ganha status de acontecimento, ou seja, de construção que resulta do embate entre os vários atores que compõem o campo discursivo em questão, mas cabe salientar que a emergência de qualquer acontecimento só pode ser parcialmente previsível, dada a sua especificidade (Foucault, 1999).

A construção de um discurso de verdade ligado ao campo da gestão social ao basear-se em determinados conhecimentos aceitos socialmente não se diferencia dessa lógica; porque, inseridos em um contexto em que predomina a lógica capitalista de mercado, é esperado que os atores que defendem sua manutenção tendam à construção de mecanismos que lhes garantam não só a prevalência, mas também a perpetuação da condição privilegiada. Por consequência, as ações da lógica capitalista

\footnotetext{
3 “... o poder não é uma instituição e nem uma estrutura, não é uma certa potência de que alguns sejam dotados: é o nome dado a uma situação estratégica complexa numa sociedade determinada” (Foucault, 1993, p. 89).
} 
geram um movimento de resistência por parte daqueles atores que buscam a inversão das posições que ali se apresentam.

Assim, pensar a questão do conhecimento no campo da gestão social passa pelo entendimento sobre a forma de sua apropriação pelos indivíduos que compõem o campo discursivo, ou seja, pelos métodos previstos para disseminação/acumulação, pensamento, adequação e/ou utilização de determinada verdade tornada disponível.

\section{Gestão social e lógica capitalista: sob quais premissas?}

O campo da gestão social está repleto de práticas diversas (Fischer, 2002). Nesse sentido, serão examinadas algumas das formas de articulação, sob a ótica do referencial foucaultiano, da formação discursiva que busca, a partir dos interesses econômicos, integrar a gestão social ao processo de desenvolvimento proposto, ou mesmo tornar o social fonte localizada de reforço do sistema capitalista de mercado.

Cabe salientar que o discurso predominante sobre desenvolvimento, que encontra no Banco Mundial seu principal articulador em escala mundial, busca, a partir da década de 1970, minimizar as resistências advindas dos países qualificados como subdesenvolvidos ${ }^{4}$ por meio da incorporação de aspectos sociais como os ligados à sustentabilidade das políticas de cunho econômico.

Naquele contexto, o discurso sistêmico como aporte teórico que predominou na corrente de pensamento que visava à integração da gestão social com a lógica capitalista de mercado necessita ser minimamente caracterizado para que se entendam os pressupostos que são subjacentes ao discurso predominante.

Cabe destacar que o referencial sistêmico ao possuir seu suporte teórico na metáfora orgânica assemelha os sujeitos e organizações aos organismos biológicos. A questão que ganha ênfase é a relação desses sujeitos ou organizações com seu ambiente, ou melhor, sua capacidade de sobrevivência no ambiente, que é definida pelos níveis observados de adequação e eficiência. Essa ideia pressupõe, com base na teoria evolucionista, que os mais adaptados terão melhores chances de competir e, por consequência, de sobreviver.

0 conceito de sistema surge com Bertalanffy (1977), através de sua teoria geral dos sistemas; apesar das readequações que o conceito sofreu ao longo do tempo, mantém-se a ideia central de que no sistema, como nos organismos biológicos, já estão estabelecidos os padrões prioritários de seu desenvolvimento e, principalmente, que o sujeito e as organizações devem buscar formas de se integrar ou de se manter integrados ao sistema. 0 ambiente, por sua vez, estimulará a integração e adaptação dos fatores que emergirem no caminho de forma a manter as características sistêmicas essenciais. Nesse sentido, a posição do sujeito, assim como do próprio sistema como um todo, é de contínua adequação, porém de forma sintônica a um padrão evolutivo que deve ser atendido.

É relevante, nesse ponto, salientar que uma metáfora é uma forma aproximativa utilizada como recurso para o entendimento de determinada situação, assim como para sua comparação com outras. Entretanto, a forma como o modelo orgânico é tornado único e utilizado, em muitos momentos, poderia ser assemelhado à proposta de Descartes (2006), que, ao buscar um modelo esclarecedor único, funde o ser e sua representação. Dessa forma, a visão orgânica passa a ser um modelo norteador.

Nessa perspectiva, está o modelo de gestão social proposto pelo Banco Mundial, que emerge com o objetivo de promover a confluência dos sistemas econômico e social com vista ao desenvolvimento integral da sociedade. Entretanto, o desenvolvimento pressuposto passa pela integração do aspecto social à lógica capitalista de mercado, através do aprimoramento de instrumentos de gestão que devem

\footnotetext{
40 presidente dos EUA, Harry S. Truman, em 1949, utiliza o termo para dividir e qualificar os países entre "desenvolvidos" e "subdesenvolvidos". Entretanto, "Truman não foi o primeiro a usar a palavra. Wilfred Benson, antigo membro do secretariado da Organização Mundial do Trabalho, foi quem provavelmente a inventou quando, em 1942, ao escrever suas bases econômicas para a paz se referiu às áreas subdesenvolvidas" (Esteva, 2007, p. 7). Segundo essa autora, é a partir do discurso de Truman que o termo "desenvolvimento" passa a ser valorizado institucionalmente como oposição e, ao mesmo tempo, modelo comparativo em relação ao subdesenvolvimento.
} 
direcionar-se para a eficiência e eficácia das práticas sociais (Banco Mundial, 1978).

Destaca-se, nessa proposta, que o interesse pela redistribuição de renda ou as preocupações sociais visam, prioritariamente, à manutenção de um nível mínimo de investimento voltado à continuidade do sistema, ou seja, que o torne além de lucrativo, sustentável (Banco Mundial, 2008). Tal proposta confirma a tese de Foucault (1993a) de que as formações discursivas predominantes buscam, por intermédio das mais variadas estratégias, manutenção e perpetuação de sua posição privilegiada.

A manutenção da proposta hegemônica passa por um leque de alianças sociais em busca de articulações que possibilitem a emergência de novas perspectivas ao sistema predominante em exercício. Essas alianças, ao propiciarem condições para a perpetuação do sistema, exigem investimento no ser humano, ou seja, em sua saúde, cultura, lazer, informação (GIFE, 2007). Dessa forma, o social passa a ser visto como uma das dimensões imprescindíveis à reprodução social.

Cabe salientar o sucesso dessa estratégia, dada a importância econômica que o setor social vem adquirindo ao longo do tempo. Segundo Dowbor (2006), apenas nos EUA, 14\% do PIB está vinculado de alguma forma ao setor de saúde. Assim, merece destaque a ênfase atribuída ao desenvolvimento social com um fim em si mesmo, invertendo a lógica e posicionando o aspecto econômico como um meio (Sen, 2000).

Entretanto, daí emerge a seguinte questão: o desenvolvimento social ganha ênfase por ser uma preocupação que está ligada à própria manutenção da vida em si mesma, conforme propalado, ou ganha espaço e possibilidade de emergência por ter se tornado economicamente atraente?

Se, por um lado, a contribuição da mudança proposta passa a valorizar políticas ligadas à melhoria de vida; por outro, torna a área social central para o desenvolvimento e os resultados visualizados na esfera social tornaram-se critérios de avaliação política que medem o desenvolvimento em qualquer parte do planeta. Dessa forma, o social, a serviço da lógica capitalista, foi integrado aos mecanismos avaliativos relacionados ao desenvolvimento e incorporado à produção econômica vinculada com a área de serviços, por exemplo: em esferas como educação e saúde, que vêm tornando-se importantes setores econômicos (Amin, 2006).
Cabe salientar, ainda, que tais critérios avaliativos são construídos em países considerados desenvolvidos - frequentemente estimuladores das propostas de desenvolvimento. Apesar do discurso que defende a importância da adequação local dos esforços, utilizam-se indicadores padronizados que se transformam em instrumentos de comparação e regulação para os mais variados países ao redor da esfera terrestre (Amin, 2006).

Nesse aspecto, por exemplo, Amin (2006) considerou que as metas do milênio (PNDU, 2008) não seriam alcançáveis sem que houvesse alterações na lógica vigente em escala global. Para Amin (2006, s/p.), o primeiro objetivo, de redução em $50 \%$ da pobreza extrema e da fome, não seria mais do que “... magia enquanto as políticas que geram a pobreza não forem analisadas, denunciadas e forem propostas políticas alternativas...." Do mesmo modo, os processos de cooperação para o desenvolvimento, ao serem pensados de forma articulada com os princípios do livre-mercado, tornam-se sinônimo “... de submissão às demandas do poder imperialista. A integração no mercado é mensurada pela participação das exportações no produto interno bruto (um acréscimo nesse indicador é muitas vezes sinônimo de crescimento sem consideração com seu preço social!)" (Amin, 2006, s/p.).

Amin (2006, s/p.) afirmou, ainda, que para “... levar adiante essa 'parceria liberal' é necessário, ao final, nada mais do que a luta contra a pobreza (o único objetivo 'social' tolerado)". Por essa razão, o autor argumentou que as Metas do Milênio se constituíram em parte de um discurso que busca legitimar e tornar consensuais políticas direcionadas à expansão dos mercados capitalistas, assim como manter as posições privilegiadas dali advindas.

Sob tais premissas, a proposta de valorização de processos ligados à gestão social caracteriza-se pela articulação dos vários interesses sob a lógica capitalista que busca, ao não questionar o sistema vigente, amenizar suas consequências ou incorporá-las de forma a fazê-las funcionar como suporte ao sistema predominante vigente no contexto.

\section{0 papel do Banco Mundial e sua influência nos pro- cessos de cooperação técnica}

O processo discutido acima toma conotações globais pela ênfase que é dada por organismos 
financiadores internacionais para a esfera social, principalmente ao definir o processo de cooperação técnica como vinculado à promoção do desenvolvimento. Nesse sentido, cooperação técnica relacionada à esfera social é entendida por Lopes (2005) como um instrumento cooperativo em prol do desenvolvimento, ou seja, busca a melhoria das capacidades humanas, organizacionais e institucionais, a partir da transferência, adaptação e uso de habilidades, conhecimentos e tecnologia.

Com o propósito de articular as ações ligadas ao social, o Banco Mundial, que inicialmente direcionou seus esforços para a reconstrução da Europa pós-guerra, foi ganhando gradativamente amplitude de ação global e alterando seus objetivos para focar-se na redução da pobreza no "mundo em desenvolvimento" (Banco Mundial, 2006).

Cabe destacar que a legitimação da posição central ocupada pelo Banco Mundial, no campo discursivo do desenvolvimento desde a década de 1970, deu-se através da construção de um discurso abrangente e consensual desdobrado em termos setoriais e que teve por base dois fatores decisivos: a construção de redes de profissionais reconhecidos em sua área de atuação, e a capacidade de mobilização de recursos com vista ao financiamento de programas de desenvolvimento com as condicionalidades dali advindas (Banco Mundial, 1990 e 1991; Misoczky, 2002; Bueno, 2006).

Tal posição possibilitou ao Banco Mundial destaque na elaboração de documentos políticos e produção teórico-conceitual de noções como: desenvolvimento sustentável, cooperação técnica e pobreza (Fonseca, 1998). Esses termos que têm por função o suporte da visão e do projeto político direcionado aos países em desenvolvimento, ou, nas palavras de Foucault (1993), à produção de um determinado discurso verdadeiro que busca disseminar-se de forma ilimitada e legitimar-se como hegemônico.

O Banco Mundial, a partir da década de 1970, realizou reformas organizacionais com vista à ampliação de sua área de influência política. Na década de 1970, as mudanças focaram-se nas práticas que buscavam a igualdade de oportunidades sob o controle do Estado, alteração essa efetivada em razão do não alcance dos índices de desenvolvimento almejados para os países alvo dos investimentos. Naquele momento, o então presidente do Banco Mundial considerou que os
... objetivos são intrinsecamente relacionados, embora os governos frequentemente prestem mais atenção a um fator, em detrimento do outro. Sob o ponto de vista do desenvolvimento, tal abordagem sempre falha ao final, pois a priorização do crescimento sem uma preocupação adequada com a igualdade é socialmente desestabilizadora e, frequentemente, violenta; já, a focalização da igualdade sem a preocupação com o crescimento tende a estagnação econômica (McNamara, 1980, p. 17).

Naquele contexto, durante a década de 1970, as adequações percebidas nas práticas do Banco Mundial buscaram tornar o social alvo prioritário de seus créditos. Como estratégia política foi adotado o enfoque integrado, onde a ênfase recaía no crescimento, na demografia e na sustentabilidade. Sob tal lógica, os países considerados desenvolvidos justificavam a imposição de condições aos países em desenvolvimento, sob o discurso de que os problemas vigentes em um determinado país afetariam o sistema como um todo (Banco Mundial, 1978).

Conforme o discurso que predominou no campo discursivo em pauta, a solução para o problema da pobreza dependia mais da produtividade dos pobres que do crescimento experimentado pelo país. Lógica que delegou a responsabilidade pelas consequências do modelo adotado - regido pelas leis "naturais" do mercado - aos governos locais e à própria população.

Naquele momento, entrou em vigor o enfoque "realista", baseado nas seguintes premissas: a) centralidade do Estado; b) função do poder; e c) anarquia internacional (Nogueira \& Messari, 2005). Entretanto, o enfoque sistêmico não perde valor, razão pela qual começam a ganhar visibilidade modelos baseados na interdependência. Assim, a definição de modelos com base nos países desenvolvidos passa a ser vista a partir da "lógica realista", que supõe o equilíbrio sistêmico e na qual predomina a estratégia do pertencimento a partir da observação de normas regidas pelo princípio da equidade.

Fica explícito que os interesses econômicos deveriam ser priorizados quando relacionados com os valores de ordem humanitária, assim como o poder de influência do banco é salientado, no final da década de 1980, ao direcionar as ações do Banco Mundial para o desenvolvimento sustentado (Banco Mundial, 1987).

Tal proposta, ao ser operacionalizada na esfera social, se utilizou de processos de cooperação 
técnica que envolveram vários organismos bilaterais e multilaterais, cuja participação é justificada pelo conhecimento que possuem; por outro lado, esses organismos impõem uma gama de condições na negociação de acordos de crédito (Misoczky, 2002). Essas condições possibilitam a vinculação entre as propostas locais e setoriais com um projeto global de desenvolvimento.

Em consonância com esse processo, cabe destacar a variável educação como meio possível para gerir e difundir ou restringir o conhecimento de forma a buscar sincronia entre as políticas locais que definem as diretrizes educacionais e a lógica econômica, em nível global, apregoada pelo Banco Mundial.

A ênfase dos esforços do Banco Mundial em relação à expansão escolar, na década de 1990, foi direcionada para dois fatores: (i) a redução das despesas do setor público com a educação, a partir da priorização do ensino básico; e (ii) a adequação dos egressos do ensino formal à demanda de empregos gerada pelo mercado. Com tais objetivos, foram desenvolvidas estratégias como o ensino de massa via rádio e televisão e a transferência, nos níveis mais elevados de ensino, dos custos para os próprios alunos (Altmann, 2002).

As sugestões do Banco Mundial (1997) recomendavam o incentivo da oferta de formação na área rural e em nível profissional extraformal para os países em desenvolvimento, e a capacitação em nível superior para os países europeus não desenvolvidos com vista ao atendimento das necessidades de emprego localizadas.

Fica, assim, evidenciada a ênfase atribuída à educação como instrumento facilitador do acesso ao mercado de trabalho, conforme as condições contextuais experimentadas e, como tal, busca definir as condições abertas a toda a população de pessoas que passam pelo processo educacional (Fonseca, 1998).

Esse processo não é proposto de maneira uniforme, mas privilegiando as características e especificidades locais, ou seja, busca ser um instrumento de perpetuação das condições desiguais observadas entre os diversos países ao redor da esfera terrestre, mantendo o status vigente em determinados grupos sociais. Grupos construídos sob a égide da identidade coletiva e que emergem da comunhão entre práticas e percepções. Discurso que, analisado sob a ótica foucaultiana, demonstra as estratégias utilizadas para perpetuação de uma prática discursiva hegemônica em escala global.

\section{A questão do capital social}

Um conceito que passou a integrar o discurso do Banco Mundial e que foi considerado estratégico a partir da década de 1990 - época em que se tenta impor um novo paradigma que possa integrar aspectos sociais, econômicos, culturais e institucionais como fatores de desenvolvimento - é o de capital social. Valorização que pode ser observada através de programas que buscam sua definição, monitoramento e mensuração (Higgins, 2005; Banco Mundial, 2005).

Para Fukuyama (2000), o conceito de capital social foi construído sob a lógica de uma rede relacional que deve ser pensada como um meio de buscar e/ou manter a eficiência funcional das economias modernas, assim como a estabilidade da democracia liberal. Para esse autor, as normas nas quais o capital social se fundamenta possuem sua base na reciprocidade potencial às relações humanas $\mathrm{e}$ abrangem desde a relação entre dois amigos até as doutrinas religiosas que envolvem multidões.

Capital social é definido como: “... uma norma atuante e informal que promove a cooperação entre dois ou mais indivíduos" (Fukuyama, 2000). Não é, entretanto, qualquer norma atuante que constitui o capital social; somente será considerada aquela norma que conduz à cooperação nos grupos a que os sujeitos pertencem e que são tradicionalmente entendidas como virtudes humanas, tais como: honestidade, manutenção de compromissos e reciprocidade.

Para Fukuyama (2000), o potencial de cooperação emerge da comunhão de normas e/ou crenças entre os integrantes do grupo a que cada agente participa. Tal funcionamento gera coesão interna, mas pode provocar situações de desconfiança ou hostilidade em relação aos sujeitos que não compartilham dos mesmos valores e/ou não são participantes do grupo. Em consequência, o capital social é mais valorizado como bem privado de determinado coletivo.

Ao associar o capital social à crença liberal democrática na liberdade de mercado, o autor defende a tese de que a função econômica do capital social é a redução dos custos de transação associados aos mecanismos de coordenação formais, como contratos ou regras burocráticas, o que é possível através do desenvolvimento de associações informais entre um grupo de pessoas.

A posição de Fukuyama $(1996 ; 2000)$ é evidentemente de manutenção da lógica liberal capitalista. 
Entretanto, as estratégias utilizadas pela lógica hegemônica predominante e que buscam a manutenção de sua posição privilegiada nem sempre são claramente explicitadas. Esse é o caso de algumas das apropriações do conceito de capital social cunhado por Bourdieu (1980) por formações discursivas dirigidas para a defesa da lógica capitalista.

Nessas apropriações do conceito de Bourdieu, apesar de serem considerados alguns de seus aspectos teóricos, não são problematizados os pressupostos que embasam o referencial adotado; em consequência, não é avaliada a adequação de tal utilização. Utilizar Bourdieu, mantendo os pressupostos subjacentes à teoria sistêmica, pode se caracterizar como distorção da base teórica sobre a qual se assenta toda a construção desse autor.

Cabe salientar, para reduzir a possibilidade de entendimentos equivocados, que não há uma defesa incondicional da coerência teórica desvinculada da experiência prática do dia a dia, o que estaria em contradição com o conceito de prática discursiva proposto por Foucault; o que há é uma coerência teórica que possibilite construções relacionais menos ingênuas em sua articulação com as bases teóricas.

Nesse sentido, enquanto o referencial sistêmico busca a integração e adaptação dos mais variados aspectos com base na metáfora orgânica, considerada inquestionável, Bourdieu (2005, p. 15) defende que:

A destruição deste poder de imposição simbólico radicado no desconhecimento supõe a tomada de consciência do arbitrário, quer dizer, a revelação da verdade objetiva e o aniquilamento da crença: é na medida em que o discurso heterodoxo destrói as falsas evidências da ortodoxia, restauração fictícia da doxa, e lhe neutraliza o poder de desmobilização, que ele encerra um poder simbólico de mobilização e de subversão....

No referencial sistêmico o organismo ganha status de modelo a ser seguido; como construção de uma ordem convencional dos signos, é definida como formação discursiva (Foucault, 2000a) ou crença (Bourdieu, 2005). Nesta última perspectiva, caracteriza-se como uma das alternativas presentes no contexto. Considerando, entretanto, que por estar contextualmente posicionada numa situação privilegiada em relação às demais lógicas terá um poder maior de mobilização, principalmente daqueles sujeitos que não visualizam alternativas.

Para Fukuyama (2000), o potencial de cooperação emerge da comunhão de normas e/ou crenças entre os integrantes de um coletivo que gera coesão interna ao grupo, mas também pode provocar situações de desconfiança ou hostilidade em relação aos sujeitos externos ao grupo. Por consequência, o capital social é menos valorizado como bem público do que os capitais físicos ou humanos, já que ele tende a produzir mais efeitos negativos em relação aos agentes externos ao grupo do que as outras duas formas de capital.

Nesse ponto reside outra das diferenças inconciliáveis entre a abordagem de Fukuyama e a teoria dos campos de Bourdieu. A primeira busca integrar os mais variados fatores ao ambiente macro, porém selecionando aqueles aspectos/características que são sintônicos ao contexto idealizado daqueles que são distônicos e que ficarão às margens do sistema. Já na ótica de Bourdieu (1980, p. 2) capital social é:

... o conjunto de recursos atuais ou potenciais que são possuídos por uma rede durável de relações mais ou menos institucionalizadas de interconhecimento e inter-reconhecimento; ou, em outros termos, o pertencimento a um grupo, como conjunto de agentes que não são somente dotados de propriedades comuns (suscetíveis de serem diferenciadas por observadores, outros ou por si-mesmos), mas são, também, unidos por ligações permanentes ou úteis.

0 autor complementa dizendo que tais ligações são irredutíveis às relações objetivas de proximidade - como os espaços físicos, sociais ou as condições econômicas - , já que o capital social é fundado no intercâmbio tanto em nível material quanto simbólico. Por essa razão é que a criação e perpetuação das redes supõem o reconhecimento entre os sujeitos, que produz pertencimento.

0 volume de capital social que um sujeito possui dependerá da extensão da rede de relações que ele pode mobilizar e do volume de capital econômico, cultural ou simbólico possuído. 0 capital social não é independente das outras formas de capital e do inter-reconhecimento de uma homogeneidade grupal que exerce efeito multiplicador sobre o capital possuído.

0 ganho resultante da atividade e/ou ligação a um determinado grupo tem por base a solidariedade conquistada, por causa da sensação de pertencimento entre seus integrantes, mesmo quando tais resultados não são conscientemente percebidos como consequência da ligação existente (Bourdieu, 1980).

Bourdieu (1980) defende, ainda, que a existência de redes de relação é resultado do trabalho estratégico 
de instauração e manutenção de relações duráveis e úteis à procura de proveito material ou simbólico. Tais relações, em virtude da sensação de pertencimento a um determinado grupo, acabam por produzir coisas que são transformadas em sinais de reconhecimento comuns aos seus integrantes, assim como define as fronteiras do grupo; estas são guardadas por seus componentes por meio, por exemplo, da definição de critérios para a entrada de novos membros ou da definição de regras de funcionamento interno.

Ao definir as possibilidades de entrada e as condições de participação interna, os princípios que facilitaram o desenvolvimento do grupo, em prol da concentração de recursos, o protegem também da concorrência interna, através da qual cada integrante busca apropriar-se do capital produzido pelo coletivo. Busca-se, assim, a regulação das práticas grupais, ou melhor, formas de definição em relação aos meios pelos quais os sujeitos podem se apropriar individualmente do capital coletivo, mediante a criação de mecanismos de delegação e representação (Bourdieu, 1980).

Com base em Foucault (1993), pode-se pensar, assim, na emergência de uma formação discursiva na qual os diversos atores estão em luta constante, buscando a conquista e/ou manutenção de posições privilegiadas nos mais variados níveis. Nesse sentido, a cooperação que Fukuyama atribui ao capital social, assim como suas consequências indesejáveis, não é privilégio de uma das formas de capital, mas o resultado de regras dinâmicas que atravessam todos os atores e fatores inseridos no campo discursivo em pauta.

\section{Considerações finais}

O conceito de gestão social é constituído por formações discursivas estrategicamente localizadas e, no que tange ao discurso capitalista, tende a ser integrado em práticas desenvolvimentistas com base na economia de mercado capitalista. Nesse sentido, é utilizado como instrumento gerencial que, articulado com a lógica predominante, visa ao aumento da eficiência e da eficácia das práticas discursivas internas a determinado campo discursivo, buscando, assim, a simples manutenção e/ou atualização da lógica capitalista predominante.

As práticas discursivas que buscam o desenvolvimento com base na economia de mercado capitalista ao intentarem a integração de aspectos sociais almejam, por um lado, um meio através do qual os efeitos indesejados possam ser geridos de forma a perpetuar o sistema e; por outro, incorporar tais efeitos em uma esfera que, sintônica com as regras de mercado, acaba por transformá-los em produtos/serviços rentáveis.

Assim, em sintonia com a análise de Foucault (1993), as formações discursivas que predominam em nosso contexto ao comporem um campo discursivo no qual constantemente atravessam e são atravessadas por outras formações discursivas, com as quais podem entrar em conflito, buscam continuamente estratégias de manutenção da condição privilegiada. 0 que se observa, nesse caso, é uma estratégia na qual os fatores opositivos (consequências sociais do capitalismo) são convertidos, por uma inversão que se assenta numa formação discursiva considerada verdadeira (lógica de mercado), em aspectos (políticas de redução dos riscos sociais) que dão suporte à lógica predominante.

Em contraponto, uma determinada formação discursiva, ao emergir, sempre abre brechas a partir de percepções ou interesses diferenciados que buscam resistir à lógica predominante (Foucault, 1993). Uma dessas brechas, assinalada neste texto, se refere à emergência do conceito de capital social, conforme proposto por Bourdieu (1980), que ao ser valorizado como explicativo de alguns dos efeitos indesejáveis do sistema capitalista acaba por abrir espaços de questionamento.

O espaço pressuposto pode provocar a construção de novas formações discursivas que emergem dos atravessamentos entre as duas lógicas: uma que vê o contexto como definido a priori e ao qual o sujeito deve se adaptar; e outra que defende a possibilidade de questionamento de qualquer formação discursiva, entendida como construção relacional.

0 texto que ora finda foi pensado como um espaço de resistência em relação à lógica que busca qualificar uma determinada formação discursiva como única, ou melhor, que tem o referencial sistêmico como suporte discursivo que visa à integração das mais variadas nações a uma única lógica macroeconômica, a qual busca articular os saberes e conhecimentos a uma unidade soberana.

Por fim, cabe salientar os limites deste texto que se apresenta sem a pretensão de esgotar o assunto, principalmente em uma temática tão ampla quanto a que foi proposta; mas que, mesmo nas poucas páginas que possibilitam um artigo, pretende 
provocar algumas questões e reflexões sobre esse tema amplo, tendo a certeza de que muito caminho há para ser trilhado.

\section{Referências}

Altmann, H. (2002). Influências do Banco Mundial no Projeto Educacional Brasileiro. Revista Educação e Pesquisa, 28(1), 77-89.

Amin, S. (2011). The Millenium development goals: A critique from the south. Monthy Review 57(10). Recuperado em 20 fev. 2011, de http://monthyreview.org

Banco Mundial. (1978). World Development Report 1978. Washington DC: World Bank. Recuperado em $10 \mathrm{dez}$. 2010, de http://wordlbank.org

Banco Mundial. (1987). World Development Report 1987. Washington DC: World Bank. Recuperado em $10 \mathrm{dez}$. 2010, de http://wordlbank.org

Banco Mundial. (1997). World Development Report 1997 State. Washington DC: World Bank. Recuperado em 10 dez. 2010, de http://wordlbank.org

Banco Mundial. (2011). What is Social Capital? Recuperado em 27 dez. 2011, de http://wordlbank.org

Banco Mundial. (2010). O que é o Banco Mundial? Recuperado em 14 jun. 2011, de http://www.obancomundial.org/index.php/content/view/6.html

Banco Mundial. (2008). World Development Report 2008. Washington DC: World Bank. Recuperado em $10 \mathrm{dez}$. 2010, de http://wordlbank.org

Barros, R. P., Henriques, R., \& Mendonça, R. (2000). Desigualdade e pobreza no Brasil. Revista Brasileira de Ciências Sociais, 15(42), 123-142.

Bertalanffy, L. V. (1977) Teoria geral dos sistemas. Petrópolis: Vozes.

Boudon, R. (1977). Effets Pervers et ordre social. Paris: PUF.

Bourdieu, P. (1980). Le capital social. (1980). Actes de la Recherche em Sciences Sociales, 31.

Bourdieu, P. (1993). Questões de sociologia. Rio de Janeiro: Marco Zero.
Bourdieu, P. (2005). O poder simbólico. Rio de Janeiro: Bertrand Brasil.

Descartes, R. (2006). Discurso do método. Recuperado em 20 jun. 2006, de http://br.groups.yahoo.com/group/ acropolis/

Dowbor, L. (2006). Gestão Social e Transformação da Sociedade. Recuperado em 9 set. 2006, de http://www.vanzolini.org.br/seminariousp2000/dowbor.pdf

Esteva, G. (2007). Development. In W. Sachs. The Development Dictionary: A Guide to Knowledge as Power. (pp. 6-25). New York: Zed Books Ltd.

Fischer, T. (2002). Poderes Locais, Desenvolvimento e Gestão - Introdução a uma agenda. In T. Fischer. Gestão do desenvolvimento e poderes locais: Marcos teóricos e avaliação. (pp. 12-32). Salvador: Casa da Qualidade.

Fonseca, M. (1998). O Banco Mundial como referência para a justiça social no terceiro mundo. Revista da Faculdade de Educação, 24(1), 37-69.

Foucault, M. (1990). O Pensamento do exterior. São Paulo: Princípio.

Foucault, M. (1993). Microfísica do poder. Rio de Janeiro: Graal.

Foucault, M. (1993a) História da sexualidade I - A vontade de saber. Rio de Janeiro: Graal.

Foucault, M. (1996). A ordem do discurso. São Paulo: Edições Loyola.

Foucault, M. (1999). A verdade e as formas jurídicas. Rio de Janeiro: Nau.

Foucault, M. (2000a). As Palavras e as coisas. São Paulo: Martins Fontes.

Foucault, M. (2000). A Arqueologia do saber. Rio de Janeiro: Forense Universitária.

Foucault, M. (2006). Eu Sou um pirotécnico: Sobre o método e a trajetória de Michel Foucault. In R. Pol-Droit. Michel Foucault - Entrevistas. São Paulo: Graal.

Fukuyama, F. (1996). Confiança - As virtudes sociais e a criação da prosperidade. Rio de Janeiro: Rocco.

Fukuyama, F. (2000). Social capital and civil society. Washington, D.C: IMF Institute.

Gadamar, H. (1997). Verdade e método. (3. ed.). Petrópolis: Vozes. 
Gife. (2007). Investimento social privado. Recuperado em 21 mar. 2007, de http: \\www.responsabilidadesocial.com.br

Gramsci, A. (2002). Cadernos do Cárcere. (Vol. 3). Rio de Janeiro: Civilização Brasileira.

Higgins, S. S. (2005). Fundamentos teóricos do capital social. Chapecó: Argos.

Lacan, J. (1985). O eu na Teoria de Freud e na técnica a psicanálise. (2. ed.). Rio de Janeiro: Jorge Zahar Editor.

Laclau, E., \& Mouffe, C. (2001). Hegemony and socialist strategy: Towards a radical democratic politics. (2. ed.). London: Verso.

Lopes, C. (2005). Cooperação e Desenvolvimento Humano A Agenda emergente para o novo milênio. São Paulo: UNESP.
Misoczky, M. C. A. (2002). O Campo da atenção à saúde após a Constituição de 1988: Uma Narrativa de sua Produção Social. Porto Alegre: DaCasa.

Nogueira, J. P., \& Messari, N. (2005). Teoria das Relações Internacionais. São Paulo: Campus.

Rabinow, P., \& Dreyfus, H. (1995). Michel Foucault - Uma trajetória filosófica: Para além do estruturalismo e da hermenêutica. Rio de Janeiro: Forense Universitária.

Sen, A. (2000). Desenvolvimento como Liberdade. São Paulo: Companhia das Letras. 